\title{
Progression of Bio-Tribocorrosion in Implant Dentistry
}

\author{
Caroline Dini ${ }^{1 \dagger}$, Raphael C. Costa ${ }^{1 \dagger}$, Cortino Sukotjo ${ }^{2}$, Christos G. Takoudis ${ }^{3}$, \\ Mathew T. Mathew ${ }^{4}$ and Valentim A. R. Barão ${ }^{1 *}$
}

${ }^{1}$ Department of Prosthodontics and Periodontology, Piracicaba Dental School, University of Campinas (UNICAMP), Piracicaba, Brazil, ${ }^{2}$ Department of Restorative Dentistry, College of Dentistry, University of Illinois at Chicago, Chicago, IL, United States, ${ }^{3}$ Department of Bioengineering, University of Illinois at Chicago, Chicago, IL, United States, ${ }^{4}$ Department of Biomedical Sciences, College of Medicine at Rockford, University of Illinois, Rockford, IL, United States

\section{OPEN ACCESS}

Edited by:

Alessandro Ruggiero,

University of Salerno, Italy

Reviewed by:

Joanna Mystkowska, Białystok Technical University, Poland

Vamsi Krishna Balla,

Central Glass and Ceramic Research

Institute (CSIR), India

Vladimir Ivanovich Pakhaliuk,

Sevastopol State University, Russia

*Correspondence: Valentim A. R. Barão

vbarao@unicamp.br

${ }^{\dagger}$ These authors share first authorship

Specialty section: This article was submitted to

Tribology,

a section of the journa

Frontiers in Mechanical Engineering

Received: 13 September 2019 Accepted: 07 January 2020 Published: 28 January 2020

Citation:

Dini C, Costa RC, Sukotjo C, Takoudis CG, Mathew MT and Barão VAR (2020) Progression of Bio-Tribocorrosion in Implant Dentistry. Front. Mech. Eng. 6:1. doi: 10.3389/fmech.2020.00001
Oral rehabilitation devices are susceptible to bio-tribocorrosion phenomena in the oral environment due to the synergism of wear, chemical, biochemical, and microbiological processes. This review summarizes the clinical problems and advances obtained based on current scientific evidence as well as the influence of tribological fundamentals, testing methodologies, and protocols in tribocorrosion analyses. The main clinical question related to oral rehabilitation with dental implants is the treatment failure, which is influenced by material degradation. Titanium-based implants are exposed to wear and corrosion challenges in the oral environment since the implantation and along the lifetime service. The titanium (Ti) properties such as structural material, connection design, surface treatments, alloying elements are influencing factors for material behavior. In addition, wear-corrosion factors such as cyclic loads, micromovements, oral biofilm, decontamination methods are also associated with dental implants degradation. These environmental conditions to which dental implants are submitted leads to the release of Ti particles and ions with cytotoxic and harmful effects on peri-implant surrounding tissues. In this context, the current state of the art of bio-tribocorrosion over the last decade has been steadily increasing to understand material degradation. The basic test system used to translate the tribocorrosion phenomena in the oral environment to the bench consists of electrochemical and tribological synergic analysis. The mechanical (applied load, frequency, stroke distance, and number of cycles) and electrochemical (solution composition, concentration of anions, and $\mathrm{pH}$ ) test conditions are determinants for materials tribocorrosion performance. To overcome the tribocorrosion phenomena some strategies have been used such as alloying elements for Ti-alloys manufacture, surface treatments, and biomolecules immobilization. Further studies need to have the tribocorrosion analyses as the basis for new smart materials development considering the importance of such aspects for the biomaterial clinical behavior. Finally, tribological tests are relevant strategies for understanding the mechanisms of degradation in the oral environment and for providing a way to improve the clinical outcomes of dental implants.

Keywords: oral rehabilitation, dental implants, titanium, tribocorrosion, synergism, corrosion, wear 


\section{INTRODUCTION}

The bio-tribocorrosion is an emerging and multidisciplinary area of science that has been widely studied because of its clinical relevance in oral and orthopedic fields (Mathew et al., 2014a). The human body represents a challenging condition for any biomaterial due to mechanical, chemical, biochemical, and microbiological degradation processes (Apaza-Bedoya et al., 2017). In this context, bio-tribocorrosion studies can enable understanding the irreversible degradation mechanisms that biomedical devices are exposed by analyzing the synergistic effect of wear and corrosion (Marques et al., 2016; Alves et al., 2017). Hence, the bio-tribocorrosion provides valuable information on mechanisms that influence the performance of implants in biological systems (Mathew et al., 2011).

In oral environment, titanium (Ti)-based implants and prostheses represent the primary treatment for dental replacement with high long-term success rates (Zembic et al., 2014; Srinivasan et al., 2017). However, the degradation generated by the tribocorrosion process has been reported to influence the success of dental implants due to Ti-based wear cracks generation, particles, and ions release (Shemtov-Yona and Rittel, 2015). These implant degradation products can trigger unfavorable biological responses such as increase in peri-implant infection and progressive bone loss (Costa et al., 2019). Consequently, such harmful effects influence the implant lifetime and increase the failure probability (Delgado-Ruiz and Romanos, 2018; Suárez-López Del Amo et al., 2018). For this reason, the study of the bio-tribocorrosion phenomenon has been considered a relevant topic of dental research.

The main objective of this review is to provide an overview of several relevant aspects of bio-tribocorrosion in the oral rehabilitation field with dental implants. Descriptions of tribological fundamentals, testing methodologies, and protocols, as well as clinical problems and advances obtained based on current scientific evidence were summarized. Thus, this study contributes to a better understanding of the biotribocorrosion phenomena and the impact of these processes on oral devices performance.

\section{BIO-TRIBOCORROSION: AN OVERVIEW}

Tribology is an area of the mechanical engineering that studies the mechanisms of friction, lubrication, and wear of interacting surfaces that are in relative motion (Mathew et al., 2014a; Villanueva et al., 2017). Differently, the corrosion is the science that evaluates irreversible degradation of materials that occurs due to electrochemical interaction with the surrounding environment (Asri et al., 2017). The synergistic effects of the interactions between wear and corrosion on the material surface are known as "tribocorrosion" (Ponthiaux et al., 2004; Azzi and Szpunar, 2007). In other words, tribocorrosion is a science that studies the inter-relationship of wear, chemical, and electrochemical processes (Oliveira et al., 2015; Trino et al., 2018).

In implant dentistry, wear, and corrosion are two modes of materials degradation, which are well-known and widely studied (Villanueva et al., 2017). However, individual analysis of these

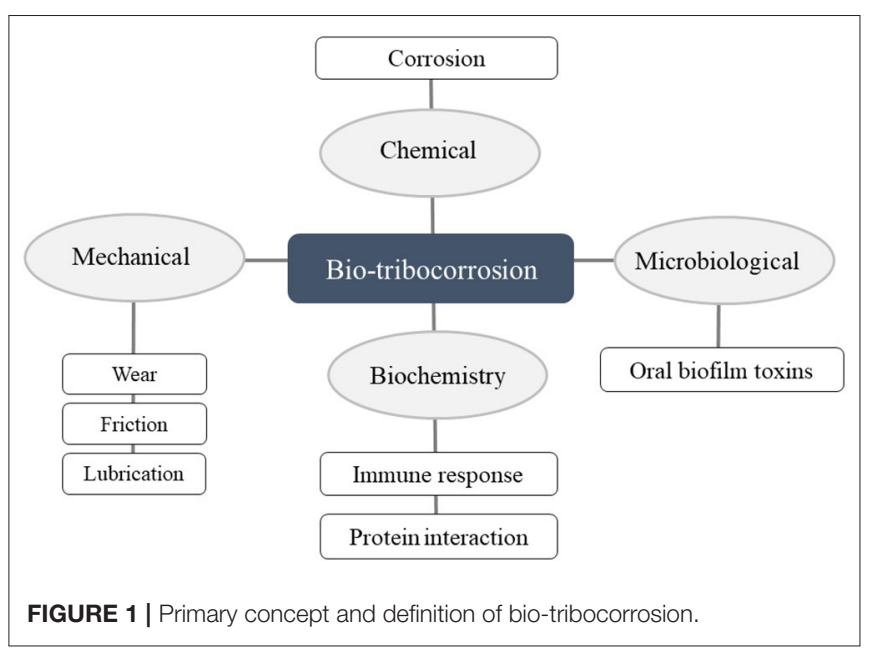

properties may not simulate the complete effect of materials degradation in the oral environment. The wear can increase the corrosion rate as well as a corrosive environment can also accelerate material loss through wear mechanisms (Oliveira et al., 2015; Souza et al., 2015). In addition, other factors related to the organism such as metabolic, immunological, biochemical, and microbiological processes can also influence the degradation of dental implants (Mathew et al., 2012b; Golvano et al., 2015). The tribocorrosion study, simulating biological conditions, is designated in the literature as bio-tribocorrosion (Mathew et al., 2012b; Souza et al., 2012; Golvano et al., 2015; Buciumeanu et al., 2016; Correa et al., 2016; Apaza-Bedoya et al., 2017; Cui et al., 2019a; Figure 1).

The bio-tribocorrosion fundamentals have been observed since the eighteenth century and were previously described as tribo-oxidations, mechanical-oxidations, and triboelectrochemistry (Ponthiaux et al., 2004; Villanueva et al., 2017). Initially, descriptions and fundamentals of tribology, corrosion, and tribocorrosion were studied separately but recently became consolidated fields in the materials sciences where the associated conditions were accounted (Villanueva et al., 2017). Over the last 20 years, the number of scientific publications about bio-tribocorrosion field increased due to diverse economic implications of this process in engineering and medical device industry (Mathew et al., 2014a; Dalmau Borrás et al., 2019).

\section{THE RELEVANCE OF BIO-TRIBOCORROSION IN DENTISTRY AND STATE OF THE ART FROM THE LAST DECADE}

Metallic biomaterials are widely used in dentistry to manufacture dental implants, abutments, frameworks, maxillofacial surgical structures, orthodontic devices, and endodontic instruments (Mathew et al., 2014a; Golvano et al., 2015; Bryant and Neville, 2017). The main problem related to these devices is the 
tribocorrosion damage to which metals are subjected in the oral environment (Souza et al., 2015). Notably, specific oral conditions make the situation more corrosive and increase the degradation process directly influencing the survival of oral treatments (Costa et al., 2019).

The state of the art of bio-tribocorrosion on dental implants field was investigated in this review through an electronic search which was conducted in three databases: PubMed, Web of Science, and Scopus. The current review used the following combination of terms "tribocorrosion OR corrosion AND dentistry AND biomaterial." Two independent reviewers screened a total of 1,284 titles and abstracts to select studies in dentistry area focused on implant dentistry field. After screening full texts, a total of 44 studies were included considering the tribocorrosion analyses for dental implants and frameworks applications. The characteristics of the 44 studies (Vieira et al., 2006; Banu et al., 2008; Richard et al., 2010; Souza et al., 2010a, 2012; Sivakumar et al., 2011; Dimah et al., 2012; Mardare et al., 2012; Mathew et al., 2012a,b; Albayrak et al., 2013; Alves et al., 2013, 2014, 2017, 2018; Benea et al., 2013, 2015, 2017; Licausi et al., 2013a,b; Fazel et al., 2015; Figueiredo-Pina et al., 2015; Golvano et al., 2015; Oliveira et al., 2015; Buciumeanu et al., 2016, 2017; Correa et al., 2016; Guinon Pina et al., 2016; Marques et al., 2016; Mindivan et al., 2016; Pontes et al., 2016; Sampaio et al., 2016b; Silva et al., 2016; Bryant and Neville, 2017; Danaila and Benea, 2017; Mindivan and Mindivan, 2018; Sikora et al., 2018; Trino et al., 2018; Wang et al., 2018; Branco et al., 2019; Corne et al., 2019; Cui et al., 2019a,b; Dalmau Borrás et al., 2019) are listed in the Supplementary Material.

The included studies from implant dentistry area have investigated the behavior of cpTi and alloys such as TiAlV, TiZr, TiNbZr, TiZrMo, TiCu, NiCrMo, CoCrMo, and CoCr for dental implants and frameworks applications. Additionally, different surface treatments have also been studied as nitriding, plasma electrolytic oxidation, hydroxyapatite coatings, sandblasting and acid etching, and biomolecules functionalization. Since the surface characteristics play an essential role for dental implants material behavior many surface modifications have been performed to achieve better wear and corrosion properties (Marques et al., 2016; Trino et al., 2018). For tribocorrosion analyses of these surfaces, a tribometer associated to a potentiostat with a three-electrode cell is commonly used, and specific mechanical and electrochemical parameters are applied. In general, surface modification engineering techniques have shown a significant improvement in the material tribo-electrochemical behavior when compared to control untreated surfaces.

Figure 2 shows that over the last decade bio-tribocorrosion studies on restorative dentistry area have been steadily increasing. From 2006 to 2019 the number of experimental and literature reviews published articles increased significantly which can be explained by issues arising the recall of dental implants and the necessity of materials with ideal properties (Oryan et al., 2014). Figure 2 also presents the literature review published articles whose content is of great importance for the understanding of tribocorrosion on restorative dentistry area. The review articles were subdivided into the main issues discussed and the 44 experimental studies above mentioned were presented according to the year of publication. In addition to the available literature, this review brings new insights regarding strategies that have been performed to overcome the tribocorrosion phenomena and summarizes the state of the art of tribocorrosion in the last decade.

\section{What Is the Oral Environment Impact in the Bio-Tribocorrosion Process?}

$\mathrm{Ti}$ and its alloys are the most commonly used materials for dental applications due to their superior biocompatibility, corrosion resistance, and excellent mechanical properties (Liu et al., 2017). These properties result from the formation of a continuous, amorphous, highly adherent, and stable titanium oxide layer $\left(\mathrm{TiO}_{2}\right)$. This film protects the metal surface against oxidative degradation processes from biological fluids (Mathew et al., 2012b; Licausi et al., 2013a). As the $\mathrm{TiO}_{2}$ native film ranges from 1 to $20 \mathrm{~nm}$ of thickness, it can be disrupted at very low shear stresses with the exposure of Ti surface to the corrosive environment (Licausi et al., 2013a; Alves et al., 2014). After being ruptured oxide layer can be recovered immediately through repassivation ( $\sim 30 \mathrm{~ms}$ ) (Apaza-Bedoya et al., 2017). However, minimal attacks are capable of depassivation, causing irreversible damages to the material (Alves et al., 2013).

The tribolayer is a mixture of organic constituents from oral fluids and metal particles present on the interface of surfaces (Wimmer et al., 2010). The stability and thickness of tribolayers are modified in a nanometer scale according to wear and corrosion degradation conditions (Salvaro et al., 2016). Tribolayers are formed as a result of the physico-chemical interactions of surfaces under relative motion with mutual transfer of materials between surfaces (Luo et al., 2009). The understanding of tribolayers stability and thickness is restricted since different contact conditions can result in different stability and destruction of tribolayers (Salvaro et al., 2016). The presence of tribolayers are beneficial for implant surface properties, since it can exert a corrosion protection (Mathew et al., 2014b). However, during the bio-tribocorrosion process the tribological forces applied on the surface can affect tribolayer stability and lead to tribofilm removal (Barril et al., 2004; Ponthiaux et al., 2004). In addition, previous study has shown the importance of tribolayers, since the oxidation of wear particles occurs primarily within the tribofilm and it can be considered the origin of wear particles (Wimmer et al., 2010). Thus, the understanding of tribolayers formation and nature is crucial to predict the tribocorrosion behavior of materials.

In this way, the tribolayer of Ti-based implants are commonly subjected to damages by tribocorrosion phenomena since the implantation and along the lifetime service (Trino et al., 2018). Firstly, material loss can occur during the implantation when friction forces are applied to implants exposed to body fluids (Suárez-López Del Amo et al., 2018). The insertion torque, loading, and implant replacement cause friction at the bone/implant interface which may be responsible for the release of metallic wear debris causing modifications to the surface and implants geometry (Franchi et al., 2004; Fretwurst et al., 2016). 


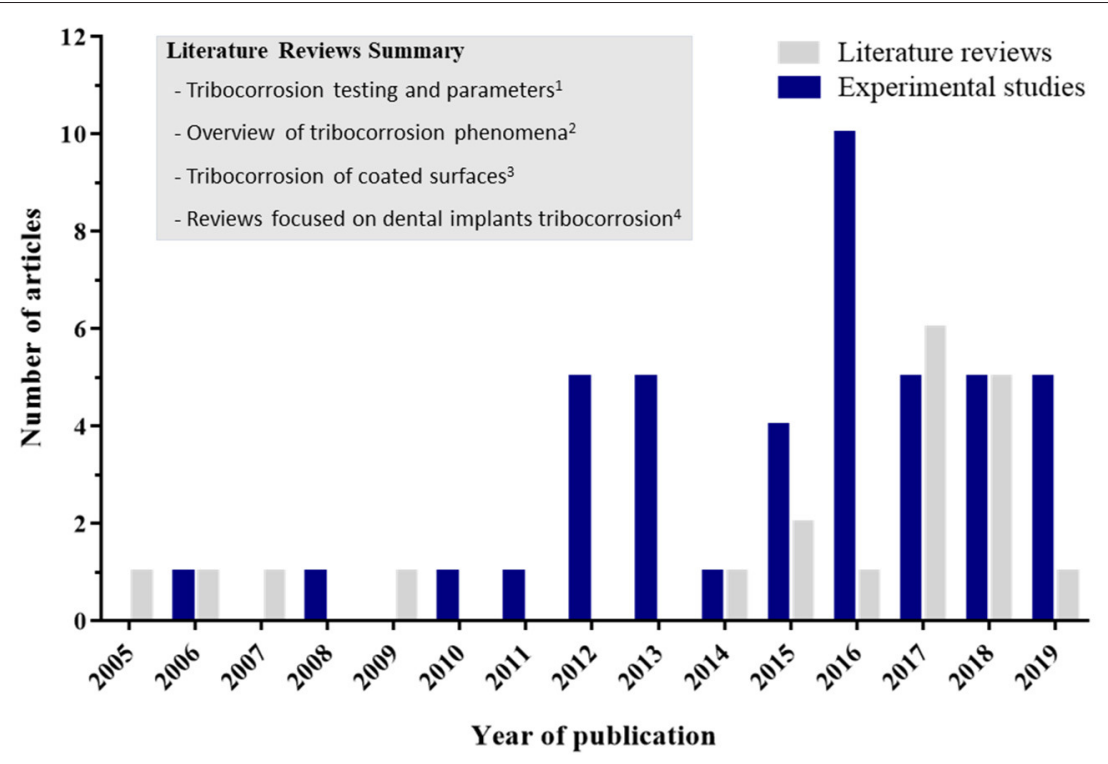

FIGURE 2 | Gray bars indicate the number of literature reviews published articles with significant discussion of tribocorrosion for restorative dentistry application. The literature reviews reference of each subtopic division are listed as follows: (1) (Celis et al., 2006; Toh et al., 2018); (2) (Mathew et al., 2014a; Dundon et al., 2017; Espallargas et al., 2017; Villanueva et al., 2017; Cao and Mischler, 2018; López-Ortega et al., 2018; Mombelli et al., 2018; (3) Stack, 2005; Wood, 2007; Wang et al., 2015; Manoj et al., 2019; and, (4) Mathew et al., 2009; Souza et al., 2015; Apaza-Bedoya et al., 2017; Balla and Das, 2017; Revathi et al., 2017; Delgado-Ruiz and Romanos, 2018; Noronha Oliveira et al., 2018). Blue bars indicate the number of tribocorrosion published articles of dental implants and frameworks materials in experimental conditions.

During chewing, physiological cyclic loads (250-450 N) (Mathew et al., 2016) can create micromovements and consequently micro-gaps between implant-abutment or abutment-prosthetic crown (Vieira et al., 2006). These micromovements induce the metal wear particle and ions release that is not entirely bioinert materials (Blum et al., 2015). The micro-gaps increase the contact of saliva and oral biofilm with implant surfaces exacerbating the corrosive process (Souza et al., 2010a; Noumbissi et al., 2019). Additionally, the characteristics of implant systems such as structural material (Souza et al., 2015; Branco et al., 2019), connection design (Mombelli et al., 2018), and surface treatments (Geringer et al., 2013) also influence the related tribocorrosion damages.

Another relevant point is that thermal, ionic, enzymatic, and microbiologic factors of the oral environment increase the corrosive behavior and electrochemical degradation of dental implants (Mathew et al., 2012b). In fact, it is well-documented that acidification of saliva (Mathew et al., 2012a; Licausi et al., 2013b), fluoride concentration (Sivakumar et al., 2011; Licausi et al., 2013a; Golvano et al., 2015), and oral mouthwashes (Pontes et al., 2016) cause damages on the surface of metallic biomaterials. In addition, chronic diseases, medications, and infection processes can influence Ti degradation by acidification around the implant (Mathew et al., 2012a). Sucrose (Souza et al., 2018), caffeine and smoking products (Barão et al., 2015) also modify saliva $\mathrm{pH}$ but have not been associated with reduced corrosion resistance of Ti. However, these factors are related to a higher formation and virulence of oral biofilm (Barão et al., 2015; Souza et al., 2018).
Specifically, it is important to state the saliva layer influence in the tribocorrosion process. Human saliva is a complex mix of fluids which consists of several inorganic and organic compounds produced by parotid, submaxillary, and submandibular glands as well as by oral mucosal glands (Dodds et al., 2005). Saliva has numerous functions including moistening of oral mucosa, lubrication during mastication, formation of food bolus, swallowing and speaking, modulation of oral microbial flora and also helps the healing of oral wounds (Dawes et al., 2015). The composition of saliva includes aminoacids (e.g., leucine, glycine, glutamate, and aspartate), proteins (e.g., albumin, proline-rich proteins, statherin, and histatin), glycoproteins (e.g., mucin), carbohydrates (e.g., sucrose, glucose, galactosis, and sialic acid), and lipids (e.g., phospholipids, triglycerides and cholesterol) (Souza et al., 2015; Branco et al., 2019). In addition, inorganic compounds such as sodium, chloride, calcium, phosphate, and bicarbonate are also saliva constituents (Dodds et al., 2005). The saliva $\mathrm{pH}$ ranges between 6 and 7 and it can decrease by presence of acidic substances and microorganisms metabolites. Under lower $\mathrm{pH}$ conditions the Ti surface is prone to degradation due to the reduction of corrosion resistance (Duffo et al., 1999; Souza et al., 2009; Beline et al., 2016). In general, acidic environment favors the ions exchange between the implant surface and saliva, inducing higher corrosion rates (Barão et al., 2012). Oppositely, in the oral environment the viscosity of saliva due to mucin presence promotes the protection of surfaces against wear (Souza et al., 2010a). Such protection is attributed to the mucin capability to form a physically crosslinked network layer that impairs the corrosion/wear by a viscoelastic and lubricating 
effect on the Ti and counterbody surfaces (Celli et al., 2005). Previous studies have shown lower friction and wear of $\mathrm{Ti}$ in the presence of human saliva (Branco et al., 2019), solution containing water, lipids, and glycoproteins (e.g., mucin) (Souza et al., 2015) and albumin (Serro et al., 2006). In addition, the inorganic components can prevent the corrosion of Ti material by maintaining the $\mathrm{pH}$ with the buffer action of bicarbonate (HCO3-) and phosphate ([PO4 $]^{3-}$ ) ions (Bardow et al., 2000). Therefore, it is important to state that saliva has a significant influence on bio-tribocorrosion process and its use is crucial on in vitro tests for a more reliable tribological response of implant materials.

Concurrently, as dental implants are exposed to the microbiota from oral environment it is feasible to expect that oral microorganisms also can influence implants bio-tribocorrosion (Figueiredo-Pina et al., 2019). After implant placement in the oral cavity, the salivary pellicle starts forming immediately onto dental implants surfaces (Dhir, 2013). Consequently, implant surface is soon colonized by oral bacteria forming biofilms (Busscher et al., 2010). The cervical area of dental implants is in contact with epithelium and fibrocollagenous soft connective tissue as well as in contact with the abutment and oral fluids (Çomute et al., 2001). Interfacial discrepancies between implants and abutments generate prosthetic gaps that can favor the microbial colonization (Souza et al., 2015). Previous studies have shown that oral fluids and biofilms in the implant internal connection and microgaps can be one of the factors responsible for abutments unscrewing, leading to an ultra-low friction on Ti under sliding (Jemt and Pettersson, 1993; Piattelli et al., 2001; Souza et al., 2010a). The biofilm is capable to protect $\mathrm{Ti}$ surface by keeping it physically separated from the counterbody under low and constant friction (Souza et al., 2010b). Such protection is attributed to the viscoelastic property of microbial cells provided by the presence of polysaccharides, proteins, phospholipids, and nucleic acids (Vinogradov et al., 2004; Cense et al., 2006).

On the other hand, acidic metabolites produced by the bacteria are related to increased tendency to corrosion of $\mathrm{Ti}$ material (Figueiredo-Pina et al., 2019). The biofilm growth and carbohydrates metabolism alter the $\mathrm{pH}$ and oxygen content by the release of acidic substances (Souza et al., 2013). Consequently, localized corrosion of $\mathrm{Ti}$ can be promoted by bacteria colonization, release of acidic substances, and pH reduction (Guindy et al., 2004; Mabilleau et al., 2006). In addition, the lowering of $\mathrm{pH}$ by lactic acid production can favor the accumulation and diffusion of fluoride ions through the biofilm extracellular matrix which increases the Ti corrosion (Watson et al., 2005; Souza et al., 2015). Souza et al. (2010b) analyzed the simultaneous wear-corrosion of $\mathrm{Ti}$ in the presence of biofilms composed of Streptococcus mutans and Candida albicans showing that $\mathrm{pH}$-lowering promoted by microbial species can lead to higher corrosion of Ti-based oral rehabilitation systems. The particles release can influence the biofilm development, bacterial endotoxins accumulation, and peri-implant inflammation (Suárez-López Del Amo et al., 2018). Mathew et al. (2012b) showed that lipopolysaccharide (LPS), which is a membrane constituent of gram-negative bacteria, affected negatively the wear/corrosion behavior of pure $\mathrm{Ti}$ and TiAlV alloy. In the same way, the natural production of hydrogen peroxide $\left(\mathrm{H}_{2} \mathrm{O}_{2}\right)$ under inflammatory responses has negative effects on $\mathrm{Ti}$ corrosion resistance (Mabilleau et al., 2006). On the whole, the higher corrosion of Ti due to bacteria and inflammatory reaction products can increase the surface roughness, favor microbial attachment, and further influence the bio-tribocorrosion of Ti material. Thus, to control the oral biofilm is a vital strategy to reduce tribocorrosion damage derived from bacterial metabolism and progressive loss of dental implant surrounding bone tissue (Souza et al., 2010b; Suárez-López Del Amo et al., 2018).

From the tribological point of view, the oral environment is extremely complex and highly aggressive for metallic implants (Mabilleau et al., 2006). The presence of saliva and microorganisms can trigger dual effects on dental implants bio-tribocorrosion. Concerning chemical and mechanical degradation, there is no consensus in the literature regarding the most important factor for the tribological behavior. It is related to the rate of material degradation that is not predicted by the wear or corrosion behavior separately, but rather by the synergistic effect of both factors. Despite the viscoelasticity of saliva and biofilm constituents provide a protective effect against friction, the $\mathrm{pH}$ reduction and bacteria metabolites can induce higher corrosion rates (Mabilleau et al., 2006; Souza et al., 2010b; Figueiredo-Pina et al., 2019). Thus, the literature suggests that the corrosion resistance is remarkably important for implant materials. Furthermore, biofilm can be detached from the surface as shear stress increases and no longer provide the protective effect of the surface (Hwang et al., 2014). Corrosion can further increase Ti dissolution particles and affect the structure and composition of the submucosal microbiome, inducing higher rates of inflammatory response (Daubert et al., 2018). Additionally, material degradation can increase crestal bone resorption and also increase the possibilities for higher amplitude of micro-movement and implant failure (Jung et al., 1996).

In the oral environment, the methods used for biofilm control and implant surfaces decontamination including mechanical, chemical, and simultaneous procedures are also potential factors to increase the surface tribocorrosion (Louropoulou et al., 2014). Currently, there is no defined gold standard for implant surface decontamination (Al-Hashedi et al., 2017). Different advantages, disadvantages, and limitations have been correlated with existing methods, and adverse effects of different magnitudes on the surfaces of implant-abutment connections can be found (Delgado-Ruiz and Romanos, 2018). Mechanical methods may cause irreversible structural destruction in dental implants (e.g., polishing, finishing, and implantoplasty) while chemical methods (e.g., chlorhexidine, citric acid, $\mathrm{H}_{2} \mathrm{O}_{2}$ ) are more related to damage of the $\mathrm{TiO}_{2}$ layer and electrochemical corrosion of the Ti surface (Noronha Oliveira et al., 2018). Further studies are encouraged to analyze the influence of decontamination methods on tribocorrosion behavior in dental implants.

Therefore, the impact of bio-tribocorrosion in the oral environment is directly related to the rupture of the $\mathrm{TiO}_{2}$ layer through the complex oral factors (e.g., cyclic loads, 
micromovements, saliva acidification, oral biofilm, and decontamination methods) with consequent loss of wear debris (e.g., particles and ions release) which leads to constant degradation of dental implants structure.

\section{Do Bio-Tribocorrosion Products Affect the Peri-Implant Tissue Reaction?}

Recent systematic reviews have confirmed the negative effect of implants degradation products on biological systems (DelgadoRuiz and Romanos, 2018; Suárez-López Del Amo et al., 2018). In fact, weakened surfaces due to the bio-tribocorrosion process may release metallic wear debris produced by the implant material degradation (Souza et al., 2015). In contact with biological fluids, the free $\mathrm{Ti}$, and metal-like particles can dissolve and generate ions that are accumulated in peri-implant bone (He et al., 2016) or migrate systemically to several organs of the body (Meyer et al., 2006). Some studies reported that $\mathrm{Ti}$ wear particles have different sizes and morphologies, from round to elongated, and ranging from 1 to $54 \mu \mathrm{m}$ that can affect the surrounding living cells and tissues (Suárez-López Del Amo et al., 2018; Costa et al., 2019). Therefore, these Ti products are mainly associated with aseptic loosening of the orthopedics implants (Meyer et al., 2006) and pathogenesis of peri-implantitis through various mechanisms (Fretwurst et al., 2016; Safioti et al., 2017).

Initially, Ti-based wear particles induce the activation of immune-system cells (monocytes, macrophages, neutrophils, and $\mathrm{T}$ lymphocytes) with the release of pro-inflammatory cytokines, such as TNF- $\alpha$, IL- $1 \alpha, 1 \beta$, IL-6, IL-10, and prostaglandin (PGE2) (Souza et al., 2015; Noronha Oliveira et al., 2018). During this biological defense process, osteoblasts are capable to internalize and phagocyte wear debris modifying the basic cell mechanisms and leading to cell necrosis (Noronha Oliveira et al., 2018). In addition, differentiation and maturation of osteoclasts induced by metal ions and particles increase the function of peri-prosthetic osteolysis (Meyer et al., 2006; Mine et al., 2010). Similarly, cytotoxic effect on bone marrow stem cells has also been previously reported (Meng et al., 2009). In peri-implant soft tissues, Ti wear particles are toxic to epithelial cells (e.g., fibroblasts) through cellular DNA damage (Noronha Oliveira et al., 2018). Hence, this process affects the integrity of the epithelial barrier, facilitating bacterial colonization, increasing the inflammatory and infectious reactions (Figure 3).

Previous studies have reported that $\mathrm{Ti}$ particles release can trigger a complex inflammatory response on peri-implant surrounding tissues (Pajarinen et al., 2013; Grosse et al., 2015). Pettersson et al. (2017) have shown a significant effect of $\mathrm{Ti}$ particles on inflammatory activation of human macrophages, resulting in the secretion of IL- $1 \beta$ from cells. Similarly, Cadosch et al. (2010) reported a negative effect of $\mathrm{Ti}$ particles on $\mathrm{T}$ lymphocytes, resulting in increased levels of osteolysis which may be a factor for implant failure. The impact on bone cell function has also been described as an unfavorable impact of Ti particles release, since osteoblasts are capable to phagocyte Ti particles leading to cell necrosis (Pioletti et al., 1999). Furthermore, not only the amount of wear debris is important but also the debris accumulation has a considerably negative effect on bone cell function and inflammatory reactions (Pioletti et al., 1999; Pajarinen et al., 2013; Grosse et al., 2015). In addition to the negative impact on peri-implant tissues, previous study has demonstrated the potential of $\mathrm{Ti}$ particles to change the bacteria colonization of Ti surfaces (Souza et al., 2019). It was demonstrated the Ti particles potential to generate microbial dysbiosis from a commensal to a pathogenic profile which favors the development of peri-implantitis. In addition, the interaction of Ti particles with the oral environment has negative effects, mainly for the peri-implant tissues (Pioletti et al., 1999; Pajarinen et al., 2013; Grosse et al., 2015; Pettersson et al., 2017; Souza et al., 2019).

Suárez-López Del Amo et al. (2018) reported that periimplantitis sites presented a higher number of $\mathrm{Ti}$ particles compared to healthy implants. This fact may be associated with the effect of Ti-based wear debris on the mechanism of periimplant disease development. In addition, it is important to highlight that although it was previously believed that $\mathrm{Ti}$ is not bacteriostatic (Fretwurst et al., 2018) some studies have already proved the potential effect of Ti particles on oral biofilm development (Bundy et al., 1980; Joshi and Eley, 1988; Elagli et al., 1992). These findings are attributed to the Ti-based wear debris that is used as substrate to bacteria adhesion and coaggregation, favoring specific bacterial growth that may increase the virulence of oral biofilm (Fretwurst et al., 2018). Moreover, allergies and hypersensitivity reactions related to Ti release in oral tissues have also been evidenced but it is unlikely that it plays a major role in the epidemiology of peri-implant diseases (Mombelli et al., 2018).

Despite recent scientific advances, there is no consensus among studies on the complete effects of Ti degradation products in the mechanisms of peri-implantitis. In fact, little is known regarding the possible cytotoxicity in human cells related to the amount, size, and chemical composition of Ti-wear debris. Moreover, the long-term biologic effect of bio-tribocorrosion in the survival of dental implants and prostheses are still unknown. Further studies are required to clarify the full role of the $\mathrm{Ti}$ degradation products in the cytotoxicity and genotoxicity in peri-implant tissues and their mechanistic model.

\section{HOW TO TRANSLATE THE TRIBOCORROSION PHENOMENA TO THE BENCH?}

Generally, studies focused in dentistry have used available systems for tribocorrosion tests. The most used are the $\mathrm{pin} / \mathrm{ball}$ on disc (unidirectional) which simulates unidirectional sliding (Stack and Chi, 2003) and the pin/ball on plate (reciprocating) which simulates the sliding under reciprocating conditions back and forth with the same wear track against the plate (Mathew et al., 2010). Figure 4 shows a schematic representation of tribometer systems. Regarding the corrosion analysis in the tribocorrosion tests, different types have been employed as cathodic condition, free potential, potentiostatic, and potentiodynamic tests (Mathew et al., 2016). The application of a potential associated with tribological forces enables to 


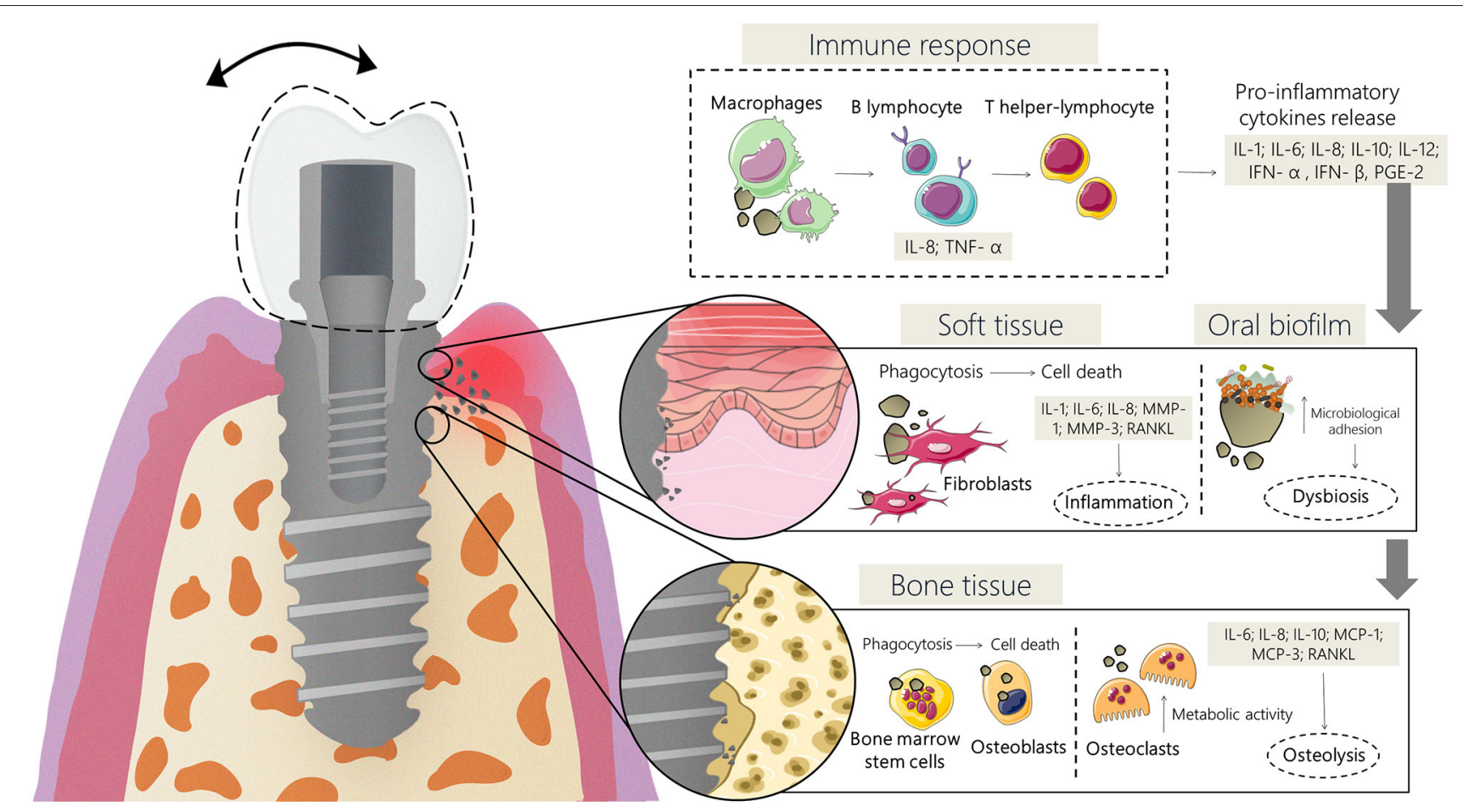

FIGURE 3 | Schematic representative diagram of the inflammatory process induced by Ti wear particles. This process causes the activation of immune-system cells (monocytes, macrophages, neutrophils, and T lymphocytes) with the release of pro-inflammatory cytokines, such as TNF- $\alpha$, IL-1 $\alpha, 1 \beta$, IL-6, IL-10, and prostaglandin (PGE2) which leads to damages in the epithelial barrier, facilitating bacterial colonization, increasing the inflammatory, and infectious reactions.

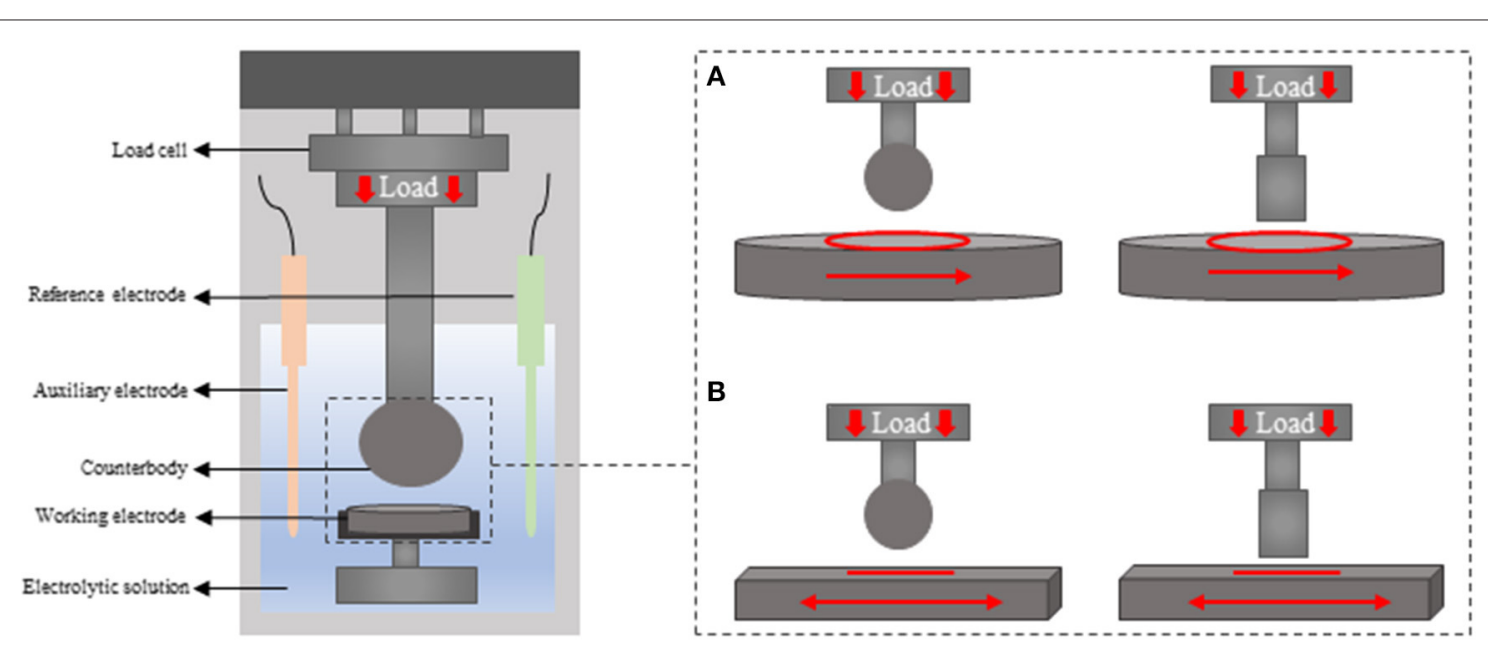

FIGURE 4 | Schematic diagram of tribocorrosion testing system (A) pin/ball on disc (unidirectional) and (B) the pin/ball on plate (reciprocating).

monitor the current generated during the corrosion tests with mechanical events (Rocha et al., 2013).

The basic test system used to translate the tribocorrosion phenomena in the oral environment to the bench consists of electrochemical and tribological synergic analysis (Mathew et al., 2011). An anodic and cathodic electric current flow is produced by converting the implant into an electrode, which increases the corrosion rate due to the high chemical reactivity of the metal (Ogawa et al., 2016). Firstly, the system is allowed to stabilize the potential and oxide film formation during which the open circuit potential (OCP) is measured (Benea et al., 2013). Later the wear tests are performed during either the OCP or potential application (Golvano et al., 2015). Lastly, the load is removed, and the OCP is measured (Corne et al., 2019). Therefore, triboelectrochemical techniques allow simulating the oxide film formation as well as different corrosion potentials 
and environmental conditions to which dental implants and frameworks can be submitted (Mathew et al., 2011; Cordeiro et al., 2017). Overall, tribocorrosion plays a vital role to understand the material behavior, wear tracks generation, and volume loss (Mischler, 2008).

\section{Tribocorrosion Test in the Laboratory}

The type of tribocorrosion testing parameters has a significant influence on material behavior (Mathew et al., 2011). Thus, it is essential to consider the mechanical and electrochemical test conditions. The type of material wear, applied load, frequency, stroke distance, and number of cycles used on in vitro studies are influencing factors for mechanical analysis (Mathew et al., 2012b). Besides, the electrolytic solution composition, concentration of anions, and $\mathrm{pH}$ are also important determinants for materials tribocorrosion performance (Chaturvedi, 2009). Notably, the synergism of mechanical and electrochemical analyses markedly increases the material degradation (Yan et al., 2006).

Concerning the types of material wear, it has been reported in the literature that tribocorrosion can be classified as fretting and erosion corrosion, abrasion corrosion, pitting corrosion, sliding corrosion, or fatigue corrosion (Chaturvedi, 2009; Sikora et al., 2018). Among the types of material wear, fretting wear, and erosion corrosion occur when contacting surfaces have a small relative motion between them under load in the presence of a solution (Eliaz, 2019). This type of material wear would occur inevitably between dental implant and bone interface during masticatory function (Gao et al., 2012). Abrasion wear is another type of material degradation related to the contact between two surfaces under relative motion in a chemically reactive environment with the presence of abrasive particles (Sampaio et al., 2016a,b). In the oral cavity, the abrasion wear can be a consequence of masticatory action and tooth brushing, forming a three-body abrasion in the presence of particles from food or toothpaste (Lambrechts et al., 2006). Wear can also be generated by more aggressive environment and penetrating forces known as pitting wear (Aksakal et al., 2004). This type of material degradation can result in the formation of localized small cavities in the material surface, being these sites more susceptible to corrosion (Olmedo et al., 2008). The fatigue wear is also a type of material degradation and it is related to contacting surfaces under high local stress due to impact or loading (Sikora et al., 2018). Another type of material degradation is the sliding corrosion which is defined as the contact of surfaces under large sliding motion and can simulate the micromotion between the implant-bone interface (Dearnley et al., 2004). Considering the types of material wear and the complex interactions occurring at the implant/abutment interface, tribocorrosion testing methodologies are crucial to understand the mechanisms of material degradation in the oral environment.

Considering the tribological parameters, at higher applied loadings an increase in the current can be observed (Mathew et al., 2011). Similarly, not only the greater stroke distance associated to higher loads but also the increase in the frequency rates significantly affect the current (Barril et al., 2004;
Swaminathan and Gilbert, 2013). Therefore, higher corrosion rates associated to higher load, frequency, and stroke distance may lead to the oxide layer destruction and consequently metal ions release (Mathew et al., 2011).

The number of cycles is another parameter that influences the creation of subsurfaces cracks and wear tracks as it increases (Dalmau Borrás et al., 2019). The wear track area increase is closely related to the corrosion rate, which depends on the rate of reaction of the metal and on the applied potential (Mischler, 2008; Mathew et al., 2011). In addition, the counter body material also affects the results, where previous study showed a higher initial wear rate and also higher total wear for $\mathrm{Ti}$ balls in comparison with zirconia balls (Corne et al., 2019). Commonly, alumina balls with different diameters are the material of choice for counter bodies due to its higher hardness, wear-resistance, and electrical insulating properties (Benea et al., 2013).

Concerning the electrochemical parameters, a variety of factors can influence the corrosion potential such as the formation of a passive oxide layer, rate of reaction, temperature, electrolytic solution, or externally imposed currents (Mischler, 2008). Therefore, depending on the environmental conditions a metal can experience different corrosion potentials and higher potentials induce the formation of thicker oxide layers (Dalmau Borrás et al., 2019). However, during tribocorrosion tests the tribological forces applied on the surface leads to the passive film removal and the interaction between worn and unworn surfaces may impact the corrosion process (Barril et al., 2004; Ponthiaux et al., 2004).

The electrolytic solution also is known to have a strong influence on the corrosion performance of $\mathrm{Ti}$ and its alloys. Notably, the composition and thickness of the oxide layer likewise the repassivation process are directly influenced by the environmental conditions (Contu et al., 2004). The acid electrolytic solutions reduce $\mathrm{H}^{+}$ions and hence induces the formation of hydrogen bubbles (Mischler, 2008). The previous study has shown greater current fluctuation at $\mathrm{pH}$ 6.0, which indicates higher tribocorrosion damage on the surface (Mathew et al., 2012a).

Finally, the synergism of wear (mechanical) and corrosion (electrochemical) parameters are determinants for the tribocorrosion analyses. Different conditions to which the material under analyses may be submitted can be translated to the bench by the tribocorrosion tests. Furthermore, it is important to consider the study purpose since for dentistry or engineering fields the tribocorrosion parameters can be adjusted to simulate the environmental conditions with greater reliability.

\section{Significant Data Extracted From the Test}

Tribocorrosion studies may provide answers regarding material mechanical performance and surface stability against corrosive environments (Apaza-Bedoya et al., 2017). During testing, the material corrosion resistance can be evaluated by electrochemical techniques such as open circuit potential (OCP) and electrochemical impedance spectroscopy (EIS) (Mathew et al., 2011). Moreover, volume loss can be estimated by profilometry and laser scanning measurements (Cui et al., 2019b; Dalmau Borrás et al., 2019). Wear track areas can also be 


\section{Strategies to overcome the tribocorrosion phenomena}

\begin{tabular}{|c|c|c|c|}
\hline \multicolumn{4}{|c|}{ Strategies to overcome the tribocorrosion phenomena } \\
\hline $\begin{array}{l}\text { Ti alloys } \\
\text { - } \beta \text {-Ti alloys: } \mathrm{Mo}, \mathrm{Zr}, \mathrm{Nb} \text { and } \mathrm{Ta}\end{array}$ & $\begin{array}{l}\text { - Low modulus, corrosion resistance and non- } \\
\text { toxicity (Revathi et al., 2017) } \\
\text { - Young's modulus closer to hard tissues, low } \\
\text { density, mechanical and chemical resistance (Li } \\
\text { et al., 2014) }\end{array}$ & Schematic diagram of $\beta$ - & $\begin{array}{l}\text { Microscale of Ti alloys } \\
\downarrow \\
\mid\end{array}$ \\
\hline $\begin{array}{l}\text { Coatings } \\
\text { - Sandblasting and acid etching } \\
\text { - Anodizing } \\
\text { - Nitriding } \\
\text { - Hydroxiapatite coatings } \\
\text { - Magnetron sputering } \\
\text { - Plasma electrolytic oxidation }\end{array}$ & $\begin{array}{l}\text { - Porous structure promotes bone in-growth (Xue } \\
\text { et al., 2007) } \\
\text { - Higher hardness, wear and corrosion resistance } \\
\text { (Revathi et al., 2017) } \\
\text { - Higher strength and toughness properties } \\
\text { (Richard et al., 2010) } \\
\text { - Chemical elements incorporation (Marques et } \\
\text { al., 2016) }\end{array}$ & $\begin{array}{c}\text { Sandblasting and acid etching } \\
\text { (1) }\end{array}$ & $\begin{array}{c}\text { Plasma electrolytic oxidation } \\
\text { o }\end{array}$ \\
\hline $\begin{array}{l}\text { Biofunctionalization } \\
\text { - Peptides } \\
\text { - Proteins } \\
\text { - Other biomolecules }\end{array}$ & $\begin{array}{l}\text { - Good biological initial response and greater } \\
\text { material corrosion resistance (Trino et al., 2018) } \\
\text { - Lubricous tribolayer which acts as a protective } \\
\text { coating (Quiram et al., 2016) } \\
\text { - Enhances hardness and strength of the surface } \\
\text { (Wang et al., 2016) }\end{array}$ & 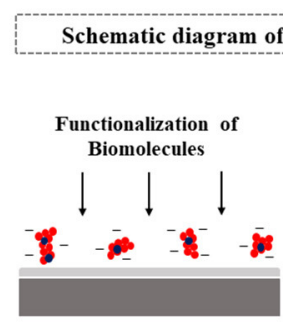 & 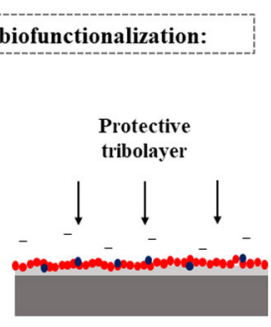 \\
\hline
\end{tabular}

FIGURE 5 | Strategies to overcome the tribocorrosion phenomena with representative imagens of titanium alloys microscale, surface treatments, and biofunctionalization of titanium surfaces.

obtained by scanning electron microscopy, optical microscope and $3 \mathrm{D}$ interferometry microscopy, which provide important information to understand the material deterioration and wear mechanisms (Mathew et al., 2016). These analyses represent an important step for the development of new materials for biomedical applications. Furthermore, as previously mentioned the tribocorrosion analyses enable to minimize peri-implant tissue reactions, hypersensitivity, cellular local inflammation, and cellular damage generated by material degradation and even the implant failure.

\section{STRATEGIES TO OVERCOME THE TRIBOCORROSION PHENOMENA}

As previously described the tribocorrosion aspects is dependent on mechanical, chemical, physical, and structural properties. Therefore, it is an outstanding effort to develop surface modifications to improve the tribocorrosion properties of $\mathrm{Ti}$ material for long-term dental implants clinical applications
(Fazel et al., 2015; Cui et al., 2019a). The use of alloying elements for Ti-alloys manufacture, surface treatments, and biomolecules immobilization are strategies that have been used to overcome the tribocorrosion phenomena (Revathi et al., 2017; Trino et al., 2018; Cui et al., 2019a). The surface modification techniques and their respective benefits against the tribocorrosion process are shown in Figure 5.

New $\mathrm{Ti}$ alloys for biomedical applications have been developed with enhanced corrosion and wear resistance, biological properties, and biocompatibility (Revathi et al., 2016). Furthermore, grinding $\mathrm{Ti}$ with other metals is a strategy to overcome the mechanical property limitation of $\mathrm{Ti}$ material (Cordeiro and Barão, 2017). The main alloying elements are $\beta$ Ti alloys using $\beta$-stabilizers such as $\mathrm{Mo}, \mathrm{Zr}, \mathrm{Nb}$, and $\mathrm{Ta}$, which are non-cytotoxic metals (Geetha et al., 2009; Revathi et al., 2016). In addition, due to characteristics including Young's modulus close to hard tissues, low density, mechanical and chemical resistance, and good osseointegration $\mathrm{Ti}$ alloys have shown characteristics closer to the ideal for use as dental implants (Li et al., 2014; Revathi et al., 2017). 
Surface modifications have also been studied in the last years to improve the tribocorrosion properties and biological response of Ti and its alloys (Marques et al., 2016; Danaila and Benea, 2017; Cui et al., 2019b). Several techniques such as plasma electrolytic oxidation, sandblasting and acid etching, magnetron sputtering, ion implantation, vapor deposition, and others have been employed to produce thick Ti coatings that can enhance the surface characteristics (Alves et al., 2014; Marques et al., 2016; Cui et al., 2019a). Coatings deposition have shown benefits from the mechanical and biological point of view with a reduction in the ions release and an increase in the corrosion and tribocorrosion resistance of Ti and its alloys (Marques et al., 2016; Danaila and Benea, 2017).

Recently, the immobilization of biomolecules has been employed as a new alternative for the development of dental implants surfaces (Trino et al., 2018). The Ti biofunctionalization with proteins and peptides has triggered good results in the initial biological response and also on the material corrosion and degradation resistance (Trino et al., 2018). The peptides immobilized on the Ti surface can act as a lubricous tribolayer which protects the surface (Quiram et al., 2016). Besides, peptides may decrease the wear rate by enhancing the hardness and strength of the top surface (Wang et al., 2016). In this sense, peptides biofunctionalization has provided for the surface nobler electrochemical property with lower corrosion rate (Trino et al., 2018).

\section{FUTURE SCOPES}

Future studies are required to translate the complexity of the oral environmental condition to the bench considering all critical factors for the bio-tribocorrosion phenomena. The identification of the relevant factors may allow the development of a simplified tribocorrosion test, which may embody all the necessary aspects for experimental analyses. Furthermore, the creation of in vivo tribocorrosion analyses is also needed for a trial test with clinical relevance. The presence of saliva, periodontal fluids, oral biofilm, cyclic loads, and micro-movements in the oral environment create a complex condition that is experienced by the implant material. Thus, understanding the tribocorrosion driving mechanisms in such a situation is of great importance.

\section{REFERENCES}

Aksakal, B., Yildirim, O. S., and Gul, H. (2004). Metallurgical failure analysis of various implant materials used in orthopedic applications. J. Fail. Anal. Prevent. 4, 17-23. doi: 10.1361/15477020419794

Albayrak, C., Hacisalihoglu, I., Yenal vangolu, A., and Alsaran, A. (2013). Tribocorrosion behavior of duplex treated pure titanium in Simulated Body Fluid. Wear 302, 1642-1648. doi: 10.1016/j.wear.2013.01.064

Al-Hashedi, A. A., Laurenti, M., Benhamou, V., and Tamimi, F. (2017). Decontamination of titanium implants using physical methods. Clin. Oral Implants Res. 28, 1013-1021. doi: 10.1111/clr.12914

Alves, A., Rossi, A. L., Ribeiro, A. R., Toptan, F., and Pinto, A. M. (2017). Tribo electrochemical behavior of bio-functionalized $\mathrm{TiO}_{2}$ nanotubes in artificial saliva: understanding of degradation mechanisms. Wear 384-385, 28-42. doi: 10.1016/j.wear.2017.05.005
From the experimental point of view, the tribocorrosion testing systems are essential approaches for the development of new dental implants materials. Further studies need to have the tribocorrosion analyses as the basis for new smart materials creation considering the importance of such aspects for the biomaterial clinical behavior.

\section{SUMMARY}

This review is a comprehensive reference for bio-tribocorrosion in implant dentistry. The state of the art and science in bio-tribocorrosion have been summarized showing that there are many scientific advances in this field. Tribological tests are relevant strategies for understanding the mechanisms of degradation in the oral environment and provide a way to improve the clinical outcomes of dental implants. Thus, this study is a guide for researchers and materials scientists in the development of new investigations as well as for clinicians to understand the mechanisms involved in oral rehabilitation failures.

\section{AUTHOR CONTRIBUTIONS}

$\mathrm{CD}$ and RC collected the data and led the writing. VB, MM, CS, and CT made the critical review of article content and writing. All authors listed have made a substantial, direct and intellectual contribution to the work, and approved it for publication.

\section{ACKNOWLEDGMENTS}

The authors acknowledge the financial support of the Coordenação de Aperfeiçoamento de Pessoal de Nível Superior-Brazil (CAPES)-Finance Code 001 and the São Paulo State Research Foundation (FAPESP), Brazil (grant numbers 2018/04630-2).

\section{SUPPLEMENTARY MATERIAL}

The Supplementary Material for this article can be found online at: https://www.frontiersin.org/articles/10.3389/fmech. 2020.00001/full\#supplementary-material 
at titanium-based dental implant connections: a scoping review. J. Periodontal. Res. 52, 946-954. doi: 10.1111/jre.12469

Asri, R. I. M., Harun, W. S. W., Samykano, M., Lah, N. A. C., Ghani, S. A. C., Tarlochan, F., et al. (2017). Corrosion and surface modification on biocompatible metals: a review. Mater. Sci. Eng. C Mater. Biol. Appl. 77, 1261-1274. doi: 10.1016/j.msec.2017.04.102

Azzi, M., and Szpunar, J. A. (2007). Tribo-electrochemical technique for studying tribocorrosion behavior of biomaterials. Biomol. Eng. 24, 443-446. doi: 10.1016/j.bioeng.2007.07.015

Balla, V. K., and Das, M. (2017). Advances in wear and tribocorrosion testing of artificial implants and material- a review. Soc. Biomater. Artif. Organs $31,150-163$.

Banu, A., Marcu, M., and Radovici, O. (2008). Electrochemical studies on tribocorrosion behavior of a nickel-chromium-molybdenum dental alloy in artificial saliva. Rev. Roum. Chim. 53, 941-945.

Barão, V. A., Mathew, M. T., Assunção, W. G., Yuan, J. C., Wimmer, M. A., and Sukotjo, C. (2012). Stability of cp-Ti and Ti-6Al-4V alloy for dental implants as a function of saliva $\mathrm{pH}$ - an electrochemical study. Clin. Oral Implants Res. 23, 1055-1062. doi: 10.1111/j.1600-0501.2011.02265.x

Barão, V. A., Ricomini-Filho, A. P., Faverani, L. P., Del Bel Cury, A. A., Sukotjo, C., Monteiro, D. R., et al. (2015). The role of nicotine, cotinine and caffeine on the electrochemical behavior and bacterial colonization to cp-Ti. Mater. Sci. Eng. C Mater. Biol. Appl. 56:114-124. doi: 10.1016/j.msec.2015.06.026

Bardow, A., Moe, D., Nyvad, B., and Nauntofte, B. (2000). The buffer capacity and buffer systems of human whole saliva measured without loss of $\mathrm{CO}_{2}$. Arch. Oral Biol. 45, 1-12. doi: 10.1016/S0003-9969(99)00119-3

Barril, S., Mischler, S., and Landolt, G. (2004). Influence of fretting regimes on the tribocorrosion behaviour of Ti6Al4V in $0.9 \mathrm{wt} . \%$ sodium chloride solution. Wear 256, 963-972. doi: 10.1016/j.wear.2003.11.003

Beline, T., Marques Ida, S., Matos, A. O., Ogawa, E. S., Ricomini-Filho, A. P., Rangel, E. C., et al. (2016). Production of a biofunctional titanium surface using plasma electrolytic oxidation and glow-discharge plasma for biomedical applications. Biointerphases 11:011013. doi: 10.1116/1.4944061

Benea, L., Danaila, E., and Celis, J. P. (2013). "Influence of contact frequencies on corrosion behavior of Ti-6Al-4V alloy during fretting in physiological solution," in 4th IEEE International Conference on E-Health and Bioengineering (EHB) (Iasi).

Benea, L., Danaila, E., Dumitrascu, V. M., and Ponthiaux, P. (2015). “The effect of anodic oxidation treatment of $\mathrm{Ti}-10 \mathrm{Zr}$ alloy on tribocorrosion behavior in a simulated physiological solution," in 2015 E-Health and Bioengineering Conference (EHB) (Isai).

Benea, L., Danaila, E., and Ponthiaux, P. (2017). Porous $\mathrm{TiO}_{2}-\mathrm{ZrO}_{2}$ thin film formed by electrochemical technique to improve the biocompatibility of titanium alloy in physiological environment. IOP Conf. Mater. Sci. Eng. 174:012044. doi: 10.1088/1757-899X/174/1/012044

Blum, K., Wiest, W., Fella, C., Balles, A., Dittmann, J., Rack, A., et al. (2015). Fatigue induced changes in conical implant-abutment connections. Dent. Mater. 31, 1415-1426. doi: 10.1016/j.dental.2015.09.004

Branco, A. C., Moreira, V., Reis, J. A., Colaço, R., Figueiredo-Pina, C. G., and Serro, A. P. (2019). Influence of contact configuration and lubricating conditions on the microtriboactivity of the zirconia-Ti6Al4V pair used in dental applications. J. Mech. Behav. Biomed. Mater. 91, 164-173. doi: 10.1016/j.jmbbm.2018.12.009

Bryant, M., and Neville, A. (2017). Fretting corrosion of CoCr alloy: effect of load and displacement on the degradation mechanisms. Proc. IMechE Part H J. Eng. Med. 231, 114-126. doi: 10.1177/0954411916680237

Buciumeanu, M., Araujo, A., Carvalho, O., Miranda, G., Souza, J. C. M., Silva, F. S., et al. (2017). Study of the tribocorrosion behaviour of Ti6Al4V - HA biocomposites. Tribol. Int. 107, 77-84. doi: 10.1016/j.triboint.2016.11.029

Buciumeanu, M., Bagheri, A., Souza, J. C. M., Silva, F. S., and Henriques, B. (2016). Tribocorrosion behavior of hot pressed CoCrMo alloys in artificial saliva. Tribol. Int. 97:423-430. doi: 10.1016/j.triboint.2016.02.007

Bundy, K. J., Butler, M. F., and Hochman, R. F. (1980). An investigation of the bacteriostatic properties of pure metals. J. Biomed. Mater. Res. 14, 653-63 doi: $10.1002 / \mathrm{jbm} .820140511$

Busscher, H. J., Rinastiti, M., Siswomihardjo, W., and van der Mei, H. C. (2010). Biofilm formation on dental restorative and implant materials. J. Dent. Res. 89, 657-665. doi: 10.1177/0022034510368644
Cadosch, D., Sutanto, M., Chan, E., Mhawi, A., Gautschi, O. P., von Katterfeld, B., et al. (2010). Titanium uptake, induction of RANK-L expression, and enhanced proliferation of human T-lymphocytes. J. Orthop. Res. 28, 341-347. doi: $10.1002 /$ jor. 21013

Cao, S., and Mischler, S. (2018). Modeling tribocorrosion of passive metals - A review. Curr. Opin. Solid State Mater. Sci. 22, 127-141. doi: 10.1016/j.cossms.2018.06.001

Celis, J. P., Ponthiaux, P., and Wenger, F. (2006). Tribo-corrosion of materials: interplay between chemical, electrochemical, and mechanical reactivity of surfaces. Wear 261, 939-946. doi: 10.1016/j.wear.2006.03.027

Celli, J., Gregor, B., Turner, B., Afdhal, N. H., Bansil, R., and Erramilli, S. (2005). Viscoelastic properties and dynamics of porcine gastric mucin. Biomacromolecules 6, 1329-33. doi: 10.1021/bm0493990

Cense, A. W., Peeters, E. A., Gottenbos, B., Baaijens, F. P., Nuijs, A. M., and van Dongen, M. E. (2006). Mechanical properties and failure of Streptococcus mutans biofilms, studied using a microindentation device. J. Microbiol. Methods 67, 463-72. doi: 10.1016/j.mimet.2006.04.023

Chaturvedi, T. P. (2009). An overview of the corrosion aspect of dental implants (titanium and its alloys). Indian J. Dent. Res. 20, 91-98. doi: 10.4103/0970-9290.49068

Çomute, A. A., Weber, H. P., Shortkroff, S., Cui, F. Z., and Spector, M. (2001). Connective tissue orientation around dental implants in a canine model. Clin. Oral Implants. Res. 12, 433-440. doi: 10.1034/j.1600-0501.2001. 120502.x

Contu, F., Elsener, B., and Bohni, H. (2004). A study of the potentials achieved during mechanical abrasion and the repassivation rate of titanium and Ti6Al4V in inorganic buffer solutions and bovine serum. Electrochim. Acta. 50, 33-41. doi: 10.1016/j.electacta.2004.07.024

Cordeiro, J. M., and Barão, V. A. R. (2017). Is there scientific evidence favoring the substitution of commercially pure titanium with titanium alloys for the manufacture of dental implants? Mater. Sci. Eng. C Mater. Biol. Appl. 71, 1201-1215. doi: 10.1016/j.msec.2016.10.025

Cordeiro, J. M., Beline, T., Ribeiro, A. L. R., Rangel, E. C., da Cruz, N. C., Landers, R., et al. (2017). Development of binary and ternary titanium alloys for dental implants. Dent. Mater. 33, 1244-1257. doi: 10.1016/j.dental.2017. 07.013

Corne, P., De March, P., Cleymand, F., and Geringer, J. (2019). Fretting-corrosion behavior on dental implant connection in human saliva. J. Mech. Behav. Biomed. Mater. 94, 86-92. doi: 10.1016/j.jmbbm.2019.02.025

Correa, D. R. N., Kuroda, P. A. B., Grandini, C. R., Rocha, L. A., Oliveira, F. G. M., Alves, A. C., et al. (2016). Tribocorrosion behavior of $\beta$-type Ti-15Zr-based alloys. Mater. Lett. 179, 118-121. doi: 10.1016/j.matlet.2016.05.045

Costa, B. C., Alves, A. C., Toptan, F., Pinto, A. M., Grenho, L., Fernandes, M. H., et al. (2019). Exposure effects of endotoxin-free titanium-based wear particles to human osteoblasts. J. Mech. Behav. Biomed. Mater. 95, 143-152. doi: 10.1016/j.jmbbm.2019.04.003

Cui, W., Cheng, J., and Liu, Z. (2019a). Bio-tribocorrosion behavior of a nanocrystalline TiZrN coating on biomedical titanium alloy. Surf. Coat. Technol. 369, 79-86. doi: 10.1016/j.surfcoat.2019.04.036

Cui, W., Niu, F., Tan, Y., and Qin, G. (2019b). Microstructure and tribocorrosion performance of nanocrystalline TiN graded coating on biomedical titanium alloy. Trans. Nonferrous Met. Soc. China 29, 1026-1035. doi: 10.1016/S1003-6326(19)65011-9

Dalmau Borrás, A., Roda Buch, A., Rovira Cardete, A., Navarro-Laboulais, J., and Munoz, A. I. (2019). Chemo-mechanical effects on the tribocorrosion behavior of titanium/ ceramic dental implant pairs in artificial saliva. Wear 426-427, 162-170. doi: 10.1016/j.wear.2018.12.052

Danaila, E., and Benea, L. (2017). The effect of normal force on tribocorrosion behaviour of Ti-10Zr alloy and porous $\mathrm{TiO}_{2}-\mathrm{ZrO}_{2}$ thin film electrochemical formed. Mater. Sci. Eng. 209:012015. doi: 10.1088/1757-899X/209/1/012015

Daubert, D., Pozhitkov, A., McLean, J., and Kotsakis, G. (2018). Titanium as a modifier of the peri-implant microbiome structure. Clin. Implant. Dent. Relat. Res. 20, 945-953. doi: 10.1111/cid.12676

Dawes, C., Pedersen, A. M., Villa, A., Ekström, J., Proctor, G. B., Vissink, A., et al. (2015). The functions of human saliva: a review sponsored by the World Workshop on Oral Medicine VI. Arch. Oral. Biol. 60, 863-74. doi: 10.1016/j.archoralbio.2015.03.004 
Dearnley, P. A., and Dahm, A. L., Çimenoglu, H. (2004). The corrosion-wear behaviour of thermallyoxidised CP-Ti and Ti-6Al-4V. Wear 256, 469-79. doi: 10.1016/S0043-1648(03)00557-X

Delgado-Ruiz, R., and Romanos, G. (2018). Potential causes of titanium particle and ion release in implant dentistry: a systematic review. Int. J. Mol. Sci. 19:E3585. doi: 10.3390/ijms19113585

Dhir, S. (2013). Biofilm and dental implant: the microbial link. J. Indian Soc. Periodontol. 17, 5-11. doi: 10.4103/0972-124X.107466

Dimah, M. K., Devesa Albeza, F., Amigo Borrás, V., and Igual Munoz, A. (2012). Study of the biotribocorrosion behaviour of titanium biomedical alloys in simulated body fluids by electrochemical techniques. Wear 294-295, 409-418. doi: 10.1016/j.wear.2012.04.014

Dodds, M. W., Johnson, D. A., and Yeh, C. K. (2005). Health benefits of saliva: a review. J Dent. 33, 223-33. doi: 10.1016/j.jdent.2004.10.009

Duffo, G., Barreiro, M., Olmedo, D., Crosa, M., Guglielmotti, M. B., and Cabrini, R. L. (1999). An experimental model to study implant corrosion. Acta Odontol. Latinoam. 12, 3-10.

Dundon, J. M., Ramkumar, P. N., and Lajam, C. (2017). Tribocorrosion in total hip arthroplasty. JBJS Rev. 5:01874474-201703000-00002. doi: 10.2106/JBJS.RVW.16.00055

Elagli, K., Neut, C., Romond, C., and Hildebrand, H. F. (1992). In vitro effects of titanium powder on oral bacteria. Biomaterials 13, 25-27. doi: 10.1016/0142-9612(92)90090-B

Eliaz, N. (2019). Corrosion of metallic biomaterials: a review. Materials 12:E407. doi: $10.3390 / \mathrm{ma1} 2030407$

Espallargas, N., Fischer, A., Muñoz, A. I., Mischler, S., and Wimmer, M. A. (2017). In-situ Generated Tribomaterial in Metal/Metal Contacts: current understanding and future implications for implants. Biotribology 10, 42-50. doi: 10.1016/j.biotri.2017.03.006

Fazel, M., Salimijazi, H. R., Golozar, M. A., and Garsivaz Jazi, M. R. (2015). A comparison of corrosion, tribocorrosion and electrochemical impedance properties of pure $\mathrm{Ti}$ and $\mathrm{Ti} 6 \mathrm{Al} 4 \mathrm{~V}$ alloy treated by micro-arc oxidation process. Appl. Surface Sci. 324, 751-756. doi: 10.1016/j.apsusc.2014.11.030

Figueiredo-Pina, C. G., Guedes, M., Sequeira, J., Pinto, D., Bernardo, N., and Carneiro, C. (2019). On the influence of Streptococcus salivarius on the wear response of dental implants: an in vitro study. J. Biomed. Mater. Res. B Appl. Biomater. 107, 1393-1399. doi: 10.1002/jbm.b.34231

Figueiredo-Pina, C. G., Moreira, V., Colaço, R., and Serro, A. P. (2015). "Tribocorrosion in dental implants: an in-vitro study," in International Scientific Conference BALTTRIB, 2015 (Akademija). doi: 10.15544/balttrib.2015.22

Franchi, M., Bacchelli, B., Martini, D., Pasquale, V. D., Orsini, E., Ottani, V., et al. (2004). Early detachment of titanium particles from various different surfaces of endosseous dental implants. Biomaterials 25, 2239-2246. doi: 10.1016/j.biomaterials.2003.09.017

Fretwurst, T., Buzanich, G., Nahles, S., Woelber, J. P., Riesemeier, H., and Nelson, K. (2016). Metal elements in tissue with dental peri-implantitis: a pilot study. Clin. Oral Implants. Res. 27, 1178-1186. doi: 10.1111/clr.12718

Fretwurst, T., Nelson, K., Tarnow, D. P., Wang, H. L., and Giannobile, W. V. (2018). Is metal particle release associated with peri-implant bone destruction? An emerging concept. J. Dent. Res. 97, 259-265. doi: $10.1177 / 0022034517740560$

Gao, S. S., Zhang, Y. R., Zhu, Z. L., and Yu, H. Y. (2012). Micromotions and combined damages at the dental implant/bone interface. Int. J. Oral Sci. 4, 182-188. doi: 10.1038/ijos.2012.68

Geetha, M., Singh, A. K., Asokamani, R., and Gogia, A. K. (2009). Ti based biomaterials, the ultimate choice for orthopaedic implants - a review. Prog. Mater. Sci. 54, 397-425. doi: 10.1016/j.pmatsci.2008.06.004

Geringer, J., Demanget, N., and Pellier, J. (2013). From acid etching treatments to tribocorrosive properties of dental implants: do some experimental results on surface treatments have an influence on the tribocorrosion behaviour of dental implants? J. Phys. D: Appl. Phys. 46:404005. doi: 10.1088/0022-3727/46/40/404005

Golvano, I., Garcia, I., Conde, A., Tato, W., and Aginagalde, A. (2015). Influence of fluoride contente and $\mathrm{pH}$ on corrosion and tribocorrosion behavior of Ti13Nb13Zr alloy in oral environment. J. Mech. Behav. Biomed. Mater. 49, 186-196. doi: 10.1016/j.jmbbm.2015.05.008

Grosse, S., Haugland, H. K., Lilleng, P., Ellison, P., Hallan, G., and Høl, P. J. (2015). Wear particles and ions from cemented and uncemented titanium-based hip prostheses-a histological and chemical analysis of retrieval material. J. Biomed. Mater. Res. B Appl. Biomater. 103, 709-717. doi: 10.1002/jbm.b.33243

Guindy, J. S., Schiel, H., Schmidli, F., and Wirz, J. (2004). Corrosion at the marginal gap of implant-supported suprastructures and implant failure. Int. J. Oral Maxillofac. Implants 19, 826-831.

Guinon Pina, V., Amigó, V., and Igual Munoz, A. (2016). Microstructural, electrochemical and tribo-electrochemical characterisation of titanium-copper biomedical alloys. Corrosion Sci. 109:115-125. doi: 10.1016/j.corsci.2016.02.014

He, X., Reichl, F. X., Wang, Y., Michalke, B., Milz, S., Yang, Y., et al. (2016). Analysis of titanium and other metals in human jawbones with dental implants - a case series study. Dent Mater. 32, 1042-1051. doi: 10.1016/j.dental.2016. 05.012

Hwang, G., Klein, M. I., and Koo, H. (2014). Analysis of the mechanical stability and surface detachment of mature Streptococcus mutans biofilms by applying a range of external shear forces. Biofouling 30, 1079-1091. doi: 10.1080/08927014.2014.969249

Jemt, T., and Pettersson, P. (1993). A 3-year follow-up study on single implant treatment. J Dent. 21, 203-208. doi: 10.1016/0300-5712(93)90127-C

Joshi, R. I., and Eley, A. (1988). The in-vitro effect of a titanium implant on oral microflora: comparison with other metallic compounds. J. Med. Microbiol. 27, 105-107 doi: 10.1099/00222615-27-2-105

Jung, Y. C., Han, C. H., and Lee, K. W. (1996). A 1-year radiographic evaluation of marginal bone around dental implants. Int. J. Oral Maxillofac. Implants $11,811-818$

Lambrechts, P., Debels, E., Van Landuyt, K., Peumans, M., and Van Meerbeek, B. (2006). How to simulate wear? Overview of existing methods. Dent. Mater. 22, 693-701. doi: 10.1016/j.dental.2006.02.004

Li, Y., Yang, C., Zhao, H., Qu, S., Li, X., and Li, Y. (2014). New developments of Ti-based alloys for biomedical applications. Materials 7, 1709-1800. doi: $10.3390 / \mathrm{ma} 7031709$

Licausi, M. P., Igual Munoz, A., and Amigó Borrás, V. (2013a). Influence of the fabrication process and fluoride content on the tribocorrosion behaviour of Ti6Al4V biomedical alloy in artificial saliva. J. Mech. Behav. Biomed. Mater. 20, 137-148. doi: 10.1016/j.jmbbm.2013.01.019

Licausi, M. P., Igual Munoz, A., and Amigó Borrás, V. (2013b). Tribocorrosion mechanisms of Ti6Al4V biomedical alloys in artificial saliva with different $\mathrm{pHs}$ J. Phys. D: Appl. Phys. 46:404003. doi: 10.1088/0022-3727/46/40/404003

Liu, X., Chen, S., Tsoi, J. K. H., and Matinlinna, J. P. (2017). Binary titanium alloys as dental implant materials - a review. Regen. Biomater. 4, 315-323. doi: $10.1093 / \mathrm{rb} / \mathrm{rbx} 027$

López-Ortega, A., Arana, J. L., and Bayón, R. (2018). Tribocorrosion of passive materials: a review on test procedures and standards. Int. J. Corrosion 2018:7345346. doi: 10.1155/2018/7345346

Louropoulou, A., Slot, D. E., and Van der Weijden, F. (2014). The effects of mechanical instruments on contaminated titanium dental implant surfaces: a systematic review. Clin. Oral Implants Res. 25, 1149-1160. doi: 10.1111/clr.12224

Luo, Q., Zhou, Z., Rainforth, W. M., and Bolton, M. (2009). Effect of tribofilm formation on the dry sliding friction and wear properties of magnetron sputtered TiAlCrYN coatings. Tribol. Lett. 34, 113-124. doi: 10.1007/s11249-009-9415-9

Mabilleau, G., Bourdon, S., Joly-Guillou, M. L., Filmon, R., Baslé, M. F., and Chappard, D. (2006). Influence of fluoride, hydrogen peroxide and lactic acid on the corrosion resistance of commercially pure titanium. Acta Biomater. 2, 121-129. doi: 10.1016/j.actbio.2005.09.004

Manoj, A., Kasar, A. K., and Menezes, P. L. (2019). Tribocorrosion of porous titanium used in biomedical applications. J. Bio Tribo Corrosion 5:3. doi: 10.1007/s40735-018-0194-4

Mardare, E., Benea, L., and Celis, J. P. (2012). Importance of applied normal loads on the tribocorrosion behaviour of Ti-6Al-4V alloy in bio-simulated environment. J. Optoelectron. Adv. Mater. 6, 474-478.

Marques, I., da, S., Alfaro, M. F., Saito, M. T., da Cruz, N. C., Takoudis, C., et al. (2016). Biomimetic coatings enhance tribocorrosion behavior and cell responses of commercially pure titanium surfaces. Biointerphases. 11:031008. doi: 10.1116/1.4960654

Mathew, M., Kerwell, S., Afaro, M., Royman, D., Barao, V., and Cortino, S. (2016). "Tribocorrosion and TMJ TJR devices", in Temporomandibular Joint Total Joint Replacement - TMJ TJR, ed L.G. Mercuri (Chicago, IL: Springer), 251-263. 
Mathew, M. T., Abbey, S., Hallab, N. J., Hall, D. J., Sukotjo, C., and Wimmer, M. A. (2012a). Influence of $\mathrm{pH}$ on the tribocorrosion behavior of $\mathrm{CpTi}$ in the oral environment: synergistic interactions of wear and corrosion. J. Biomed. Mater. Res. B Appl. Biomater. 100, 1662-1671. doi: 10.1002/jbm.b.32735

Mathew, M. T., Ariza, E., Rocha, L. A., Vaz, F., Fernandes, A. C., and Stack, M. M. (2010). Tribocorrosion behavior of TiCxOy thin films in bio-fluids. Electrochim. Acta 56, 929-937. doi: 10.1016/j.electacta.2010.08.067

Mathew, M. T., Barão, V. A. R., Yuan, J. C. C., Assunção, W. G., Sukotjo, C., and Wimmer, M. A. (2012b). What is the role of lipopolysaccharide on the tribocorrosive behavior of titanium? J. Mech. Behav. Biomed. Mater. 8, 71-85. doi: 10.1016/j.jmbbm.2011.11.004

Mathew, M. T., Kerwell, S., Lundberg, H. J., Sukotjo, C., and Mercuri, L. G. (2014a). Tribocorrosion and oral and maxillofacial surgical devices. Br. J. Oral Maxillofac. Surg. 52, 396-400. doi: 10.1016/j.bjoms.2014.02.010

Mathew, M. T., Nagelli, C., Pourzal, R., Fischer, A., Laurent, M. P., Jacobs, J. J., et al. (2014b). Tribolayer formation in a metal-on-metal (MoM) hip joint: an electrochemical investigation. J. Mech. Behav. Biomed.Mater. 29, 199-212. doi: 10.1016/j.jmbbm.2013.08.018

Mathew, M. T., Srinivasa Pai, P., Pourzal, R., Fischer, A., and Wimmer, M. A. (2009). Significance of tribocorrosion in biomedical applications: overview and current status. Adv. Tribol. 2009:250986. doi: 10.1155/2009/250986

Mathew, M. T., Uth, T., Hallab, N. J., Pourzal, R., Fischer, A., and Wimmer, M. A. (2011). Construction of a tribocorrosion test apparatus for the hip joint: validation, test methodology and analysis. Wear 271, 2651-2659. doi: 10.1016/j.wear.2011.01.085

Meng, B., Chen, J., Guo, D., Ye, Q., and Liang, X. (2009). The effect of titanium particles on rat bone marrow stem cells in vitro. Toxicol. Mech. Methods 19, 552-558. doi: 10.3109/15376510903401716

Meyer, U., Bühner, M., Büchter, A., Kruse-Lösler, B., Stamm, T., and Wiesmann, H. P. (2006). Fast element mapping of titanium wear around implants of different surface structures. Clin. Oral Implants Res. 17, 206-211. doi: $10.1111 / \mathrm{j} .1600-0501.2005 .01184 . \mathrm{x}$

Mindivan, F., and Mindivan, H. (2018). Microstructure and tribocorrosion properties of pulsed plasma nitrided cast $\mathrm{CoCr}$ alloy for dental implant applications. Acta Phys. Pol. 134:192. doi: 10.12693/APhysPolA.134.192

Mindivan, F., Yildirim, M. P., Bayindir, F., and Mindivan, H. (2016). Corrosion and tribocorrosion behavior of cast and machine milled Co-Cr alloys for biomedical applications. Acta Phys. Pol. 129, 701-704. doi: 10.12693/APhysPolA.129.701

Mine, Y., Makihira, S., Nikawa, H., Murata, H., Hosokawa, R., Hiyama, A., et al. (2010). Impact of titanium ions on osteoblast-, osteoclast- and gingival epithelial-like cells. J. Prosthodont. Res. 54, 1-6. doi: 10.1016/j.jpor.2009. 07.003

Mischler, S. (2008). Triboelectrochemical techniques and interpretation methods in tribocorrosion: a comparative evaluation. Tribol. Int. 41, 573-583. doi: 10.1016/j.triboint.2007.11.003

Mombelli, A., Hashim, D., and Cionca, N. (2018). What is the impact of titanium particles and biocorrosion on implant survival and complications? A critical review. Clin. Oral Implants Res. 29(Suppl. 18):37-53. doi: 10.1111/clr.13305

Noronha Oliveira, M., Schunemann, W. V. H., Mathew, M. T., Henriques, B., Magini, R. S., Teughels, W., et al. (2018). Can degradation products released from dental implants affect peri-implant tissues? J. Periodontal. Res. 53, 1-11. doi: $10.1111 /$ jre.12479

Noumbissi, S., Scarano, A., and Gupta, S. (2019). A literature review study on atomic ions dissolution of titanium and its alloys in implant dentistry. Materials 12:E368. doi: 10.3390/ma12030368

Ogawa, E. S., Matos, A. O., Beline, T., Marques, I. S. V., Sukotjo, C., and Mathew, M. T. (2016). Surface-treated commercially pure titanium for biomedical applications: electrochemical, structural, mechanical and chemical characterizations. Mater. Sci. Eng. C 65, 251-261. doi: 10.1016/j.msec.2016.04.036

Oliveira, F. G., Ribeiro, A. R., Perez, G., Archanjo, B. S., Gouvea, C. P., Araújo, J. R., et al. (2015). Understanding growth mechanisms and tribocorrosion behaviour of porous $\mathrm{TiO}_{2}$ anodic films containing calcium, phosphorous and magnesium. Appl. Surf. Sci. 341, 1-12. doi: 10.1016/j.apsusc.2015.02.163

Olmedo, D. G., Duffó, G., Cabrini, R. L., and Guglielmotti, M. B. (2008). Local effect of titanium implant corrosion: an experimental study in rats. Int. J. Oral Maxillofac. Surg. 37, 1032-1038. doi: 10.1016/j.ijom.2008.05.013
Oryan, A., Alidadi, S., Moshiri, A., and Maffulli, N. (2014). Bone regenerative medicine: classic options, novel strategies, and future directions. J. Orthop. Surg. Res. 9:18. doi: 10.1186/1749-799X-9-18

Pajarinen, J., Kouri, V. P., Jämsen, E., Li, T. F., Mandelin, J., and Konttinen, Y. T. (2013). The response of macrophages to titanium particles is determined by macrophage polarization. Acta Biomater. 9, 9229-9240. doi: 10.1016/j.actbio.2013.06.027

Pettersson, M., Kelk, P., Belibasakis, G. N., Bylund, D., Molin Thorén, M., and Johansson, A. (2017). Titanium ions form particles that activate and execute interleukin-1 $\beta$ release from lipopolysaccharide-primed macrophages. J. Periodontal. Res. 52, 21-32. doi: 10.1111/jre.12364

Piattelli, A., Scarano, A., Paolantonio, M., Assenza, B., Leghissa, G. C., Di Bonaventura, G., et al. (2001). Fluids and microbial penetration in the internal part of cement-retained versus screw-retained implant-abutment connections. J. Periodontol. 72, 1146-1150. doi: 10.1902/jop.2000.72.9.1146

Pioletti, D. P., Takei, H., Kwon, S. Y., Wood, D., and Sung, K. L. (1999). The cytotoxic effect of titanium particles phagocytosed by osteoblasts. J. Biomed. Mater. Res. 46, 399-407. doi: 10.1002/(SICI)10974636(19990905)46:3<399::AID-JBM13>3.0.CO;2-B

Pontes, J. R., Alves, A. C., Toptan, F., Galo, R., and Ariza, E. (2016). Effect of commercial mouthwashes on the corrosion and tribocorrosion behaviour of a Co-Cr dental casting alloy. Mater. Corrosion 67, 305-311. doi: $10.1002 / \mathrm{maco} .201508396$

Ponthiaux, P., Wenger, F., Drees, D., and Celis, J. P. (2004). Electrochemical techniques for studying tribocorrosion processes. Wear 256, 459-68. doi: 10.1016/S0043-1648(03)00556-8

Quiram, G., Gindri, I. M., Kerwell, S., Shull, K., Mathew, M. T., and Rodrigues, D. C. (2016). Nanoscale mechanical evaluation of electrochemically generated tribolayer on CoCrMo alloy for hip joint application. J. Bio. Tribo. Corros. 2:15. doi: 10.1007/s40735-016-0045-0

Revathi, A., Borrás, A. D., Muñoz, A. I., Richard, C., and Manivasagam, G. (2017). Degradation mechanisms and future challenges of titanium and its alloys for dental implant applications in oral environment. Mater. Sci. Eng. C Mater. Biol. Appl. 76, 1354-1368. doi: 10.1016/j.msec.2017.02.159

Revathi, A., Magesh, S., Balla, V. K., Das, M., and Manivasagam, G. (2016). Current advances in enhancement of wear and corrosion resistance of titanium alloys a review. Mater. Technol. 12, 696-704. doi: 10.1080/10667857.2016.1212780

Richard, C., Kowandy, C., Landoulsi, J., Geetha, M., and Ramasawmy, H. (2010). Corrosion and wear behavior of thermally sprayed nano ceramic coatings on commercially pure Titanium and $\mathrm{Ti}-13 \mathrm{Nb}-13 \mathrm{Zr}$ substrates. Int. J. Refractory Metals Hard Mater. 28, 115-123. doi: 10.1016/j.ijrmhm.2009.08.006

Rocha, L. A., Oliveira, F., Cruz, H. V., Sukotjo, C., and Mathew, M. T. (2013). "Biotribocorrosion in dental applications", in Bio-Tribocorrosion in Biomaterials and Medical Implants, ed Y. Yan (Cambridge: Woodhead), 1-2, 104-114.

Safioti, L. M., Kotsakis, G. A., Pozhitkov, A. E., Chung, W. O., and Daubert, D. M. (2017). Increased levels of dissolved titanium are associated with peri-implantitis - a cross-sectional study. J. Periodontol. 88, 436-442. doi: 10.1902/jop.2016.160524

Salvaro, D. B., Silvério, M., Binder, C., Giacomelli, R. O., Klein, A. N., and Mello, J. D. B. (2016). Genesis and stability of tribolayers in solid lubrication: case of pair DLC-stainless steel. J. Mat. Res. Technol. 5, 136-143. doi: 10.1016/j.jmrt.2015.10.008

Sampaio, M., Buciumeanu, M., Askari, E., Flores, P., Souza, J. C. M., Gomes, J. R., et al. (2016a). Effects of poly-ether-etherketone (PEEK) veneer thickness on the reciprocating friction and wear behavior of PEEK/Ti6Al4Vstructures in artificial saliva. Wear 368-369, 84-91. doi: 10.1016/j.wear.2016.09.009

Sampaio, M., Buciumeanu, M., Henriques, B., Silva, F. S., Souza, J. C. M., and Gomes, J. R. (2016b). Comparison between PEEK and Ti6Al4V concerning micro-scale abrasion wear on dental applications. J. Mech. Behav. Biomed. Mater. 60, 212-219. doi: 10.1016/j.jmbbm.2015.12.038

Serro, A. P., Gispert, M. P., Martins, M. C., Brogueira, P., Colaço, R., and Saramago, B. (2006). Adsorption of albumin on prosthetic materials: implication for tribological behavior. J. Biomed. Mater. Res. A 78, 581-589. doi: 10.1002/jbm.a.30754

Shemtov-Yona, K., and Rittel, D. (2015). On the mechanical integrity of retrieved dental implants. J. Mech. Behav. Biomed. Mater. 49, 290-299. doi: 10.1016/j.jmbbm.2015.05.014 
Sikora, C. L., Alfaro, M. F., Yuan, J. C., Barao, V. A., Sukotjo, C., and Mathew, M. T. (2018). Wear and corrosion interactions at the titanium/zirconia interface: dental implant application. J. Prosthodont.27, 842-852. doi: 10.1111/jopr.12769

Silva, D. P., Churiaque, C., Bastos, I. N., and Sánchez-Amaya, J. M. (2016). Tribocorrosion study of ordinary and laser-melted Ti6Al4V alloy. Metals 6:253. doi: 10.3390/met6100253

Sivakumar, B., Kumar, S., and Sankara Narayanan, T. S. N. (2011). Fretting corrosion behaviour of $\mathrm{Ti}-6 \mathrm{Al}-4 \mathrm{~V}$ alloy in artificial saliva containing varying concentrations of fluoride ions. Wear 270, 317-324. doi: 10.1016/j.wear.2010.09.008

Souza, J. C., Henriques, M., Oliveira, R., Teughels, W., Celis, J. P., and Rocha, L. A. (2010a). Biofilms inducing ultra-low friction on titanium. J. Dent. Res. 89, 1470-1475. doi: 10.1177/0022034510378428

Souza, J. C., Henriques, M., Oliveira, R., Teughels, W., Celis, J. P., and Rocha, L. A. (2010b). Do oral biofilms influence the wear and corrosion behavior of titanium? Biofouling 26, 471-478. doi: 10.1080/08927011003767985

Souza, J. C., Ponthiaux, P., Henriques, M., Oliveira, R., Teughels, W., Celis, J. P., et al. (2013). Corrosion behaviour of titanium in the presence of Streptococcus mutans. J. Dent. 41, 528-34. doi: 10.1016/j.jdent.2013.03.008

Souza, J. C. M., Barbosa, S. L., Ariza, E., Celis, J. P., and Rocha, L. A. (2012). Simultaneous degradation by corrosion and wear of titanium in artificial saliva containing fluorides. Wear 292-293, 82-88. doi: 10.1016/j.wear.2012.05.030

Souza, J. C. M., Henriques, M., Teughels, W., Ponthiaux, P., Cellis, J. P., and Rocha, L. A. (2015). Wear and corrosion interactions on titanium in oral environment: literature review. J. Bio Tribo Corrosion 1-13. doi: 10.1007/s40735-015-0013-0

Souza, J. G. S., Beline, T., Matos, A. O., Oliveira, B. E. C., Ricomini-Filho, A. P., and Barão, V. A. R. (2018). Electrochemical behavior of titanium exposed to a biofilm supplemented with different sucrose concentrations. J. Prosthet. Dent. 120, 290-298. doi: 10.1016/j.prosdent.2017.10.012

Souza, J. G. S., Costa Oliveira, B. E., Bertolini, M., Lima, C. V., Retamal-Valdes, B., de Faveri, M., et al. (2019). Titanium particles and ions favor dysbiosis in oral biofilms. J. Periodontal. Res. 227:1041. doi: 10.1111/jre.12711

Souza, M. E., Lima, L., Lima, C. R., Zavaglia, C. A., and Freire, C. M. (2009). Effects of $\mathrm{pH}$ on the electrochemical behaviour of titanium alloys for implant applications. J. Mater. Sci. Mater. Med. 20, 549-52. doi: $10.1007 /$ s10856-008-3623-y

Srinivasan, M., Meyer, S., Mombelli, A., and Müller, F. (2017). Dental implants in the elderly population: a systematic review and meta-analysis. Clin. Oral Implants Res. 28, 920-930. doi: 10.1111/clr.12898

Stack, M. M. (2005). Bridging the gap between tribology and corrosion: from wear maps to Pourbaix diagrams. Int. Mater. Rev. 50, 1-17. doi: $10.1179 / 174328005 X 14302$

Stack, M. M., and Chi, K. (2003). Mapping sliding wear of steels in aqueous conditions. Wear 255, 456-465. doi: 10.1016/S0043-1648(03)00203-5

Suárez-López Del Amo, F., Garaicoa-Pazmiño, C., Fretwurst, T., Castilho, R. M., and Squarize, C. H. (2018). Dental implants-associated release of titanium particles: a systematic review. Clin. Oral Implants Res. 29, 1085-1100. doi: $10.1111 /$ clr. 13372

Swaminathan, V., and Gilbert, J. L. (2013). Potential and frequency effects on fretting corrosion of Ti6Al4V and CoCrMo surfaces. J. Biomed. Mater. Res. A 101, 2602-2612. doi: 10.1002/jbm.a.34564

Toh, W. Q., Tan, X., Bhowmik, A., Liu, E., and Tor, S. B. (2018). Tribochemical characterization and tribocorrosive behavior of CoCrMo alloys: a review. Materials 11:E30. doi: 10.3390/ma11010030
Trino, L. D., Bronze-Uhle, E. S., Ramachandran, A., Lisboa-Filho, P. N., Mathew, M. T., and George, A. (2018). Titanium surface bio-functionalization using osteogenic peptides: surface chemistry, biocompatibility, corrosion and tribocorrosion aspects. J. Mech. Behav. Biomed. Mater. 81, 26-38. doi: 10.1016/j.jmbbm.2018.02.024

Vieira, A. C., Ribeiro, A. R., Rocha, A. L., and Celis, J. P. (2006). Influence of pH and corrosion inhibitors on the tribocorrosion of titanium in artificial saliva. Wear 261, 994-1001. doi: 10.1016/j.wear.2006.03.031

Villanueva, J., Trino, L., Thomas, J., Bijukumar, D., Royhman, D., Stack, M. M. et al. (2017). Corrosion, tribology, and tribocorrosion research in biomedical implants: progressive trend in the published literature. J. Bio Tribo Corrosion 3:1. doi: 10.1007/s40735-016-0060-1

Vinogradov, A. M., Winston, M., Rupp, C. J., and Stoodley, P. (2004). Rheology of biofilms formed from the dental plaque pathogen Streptococcus mutans. Biofilms 1, 49-56. doi: 10.1017/S1479050503001078

Wang, Z., Yan, Y., and Qiao, L. (2015). Tribocorrosion Behavior of Nanocrystalline Metals - a Review. Mater. Trans. 56, 1759-1763. doi: 10.2320/matertrans.M2015280

Wang, Z., Yan, Y., Su, Y., and Qiao, L. (2016). Effect of proteins on the surface microstructure evolution of a CoCrMo alloy in bio-tribocorrosion processes. Colloids Surf. B Biointerfaces 145, 176-184. doi: 10.1016/j.colsurfb.2016.05.002

Wang, Z., Zhou, Y., Wang, H., Li, Y., and Huang, W. (2018). Tribocorrosion behavior of Ti-30Zr alloy for dental implants. Mater. Lett. 218, 190-192. doi: 10.1016/j.matlet.2018.02.008

Watson, P. S., Pontefract, H. A., Devine, D. A., Shore, R. C., Nattress, B. R., Kirkham, J., et al. (2005). Penetration of fluoride into natural plaque biofilms. J. Dent. Res. 84, 451-455. doi: 10.1177/154405910508400510

Wimmer, M. A., Fischer, A., Büscher, R., Pourzal, R., Sprecher, C., Hauert, R., et al. (2010). Wear mechanisms in metal-on-metal bearings: the importance of tribochemical reaction layers. J. Orthop. Res. 28, 436-443. doi: 10.1002/jor.21020

Wood, R. J. K. (2007). Tribo-corrosion of coatings: a review. J. Phys. D Appl. Phys. 40, 5502-5521. doi: 10.1088/0022-3727/40/18/S10

Yan, Y., Neville, A., and Dowson, D. (2006). Biotribocorrosion-an appraisal of the time dependence of wear and corrosion interactions: I. The role of corrosion. J. Phys. D: Appl. Phys. 39, 3200-3205. doi: 10.1088/0022-3727/39/ $15 / \mathrm{S} 10$

Zembic, A., Kim, S., Zwahlen, M., and Kelly, J. R. (2014). Systematic review of the survival rate and incidence of biologic, technical, and esthetic complications of single implant abutments supporting fixed prostheses. Int. J. Oral Maxillofac. Implants 29(Suppl):99-116. doi: 10.11607/jomi. 2014suppl.g2.2

Conflict of Interest: The authors declare that the research was conducted in the absence of any commercial or financial relationships that could be construed as a potential conflict of interest.

Copyright (C) 2020 Dini, Costa, Sukotjo, Takoudis, Mathew and Barão. This is an open-access article distributed under the terms of the Creative Commons Attribution License (CC BY). The use, distribution or reproduction in other forums is permitted, provided the original author(s) and the copyright owner(s) are credited and that the original publication in this journal is cited, in accordance with accepted academic practice. No use, distribution or reproduction is permitted which does not comply with these terms. 